\title{
DETEKSI FRAUDULENT FINANCIAL REPORTING MENGGUNAKAN ANALISIS FRAUD PENTAGON : STUDI KASUS PADA PERUSAHAAN MANUFAKTUR YANG LISTED DI BEI TAHUN 2014-2016
}

\author{
Erma Setiawati ${ }^{1}$ \\ Ratih Mar Baningrum ${ }^{2}$ \\ *Program Studi Akuntansi, Fakultas Ekonomi dan Bisnis, Universitas Muhammadiyah Surakarta ${ }^{1}$ \\ *Program Studi Akuntansi, Fakultas Ekonomi dan Bisnis, Universitas Muhammadiyah Surakarta ${ }^{2}$ \\ *ratihmarba1996@gmail.com
}

\begin{abstract}
This study aimed to analyze and obtain empirical evidence about the effect of pentagon fraud elements (pressure, opportunity, rationalization, competence, and arrogance) on detected fraudulent financial reporting. This research analyzes the influence of variable pressure proxied by financial stability, financial target, external pressure and personal financial needs, variable opportunity proxied by nature of industry, ineffective monitoring, and, quality of external auditor, variable rationalization proxied by change in auditor, variable arrogance proxied by frequent number of CEO's pictures.

Population of this study manufactured company in Indonesia Stock Exchange during year period 20142016 with a total sample 252 manufacture company by using purposive sampling method. Data analysis technique used was logistic regression analysis processed by using program SPSS 23 for Windows.

The results of this study show that only the variable financial target have an effect to detected fraudulent financial reporting. This study hasn't shown that financial stability, external pressure, personal financial needs, nature of industry, ineffective monitoring, quality of external auditor, change in auditor, change of directors, frequent number of CEO's pictures have an effect to detected fraudulent financial reporting.
\end{abstract}

Keywords: Fraud Pentagon, Fraud Diamond, Fraud Triangle, Fraudulent Financial Reporting, Manufactured Sector Fraud.

\section{PENDAHULUAN}

Laporan keuangan akan berfungsi maksimal apabila disajikan sesuai dengan unsur-unsur kualitatifnya, antara lain : mudah dipahami, andal, dapat dibandingkan (comparable), dan relevan. Laporan keuangan disajikan kepada para pemegang kepentingan (stakeholder) yaitu : pihak manajemen, karyawan, investor (holder), kreditor, supplier, pelanggan, maupun pemerintah. Kecurangan pelaporan keuangan merupakan suatu usaha yang dilakukan dengan sengaja oleh perusahaan untuk mengecoh dan menyesatkan para pengguna laporan keuangan, terutama investor dan kreditor, dengan menyajikan dan merekayasa nilai material dari laporan keuangan.
Keinginan untuk selalu terlihat baik oleh berbagai pihak memaksa manajemen perusahaan untuk melakukan manipulasi di bagian-bagian tertentu, sehingga pada akhirnya menyajikan informasi yang tidak semestinya yang tentu akan merugikan banyak pihak. Kecurangan-kecurangan yang dilakukan manager perusahaan untuk memanipulasi laporan keuangan disebut dengan fraud, sedangkan praktik kecurangan pelaporan keuangan itu tersendiri lebih dikenal dengan fraudulent financial reporting (Tessa dan Harto,2016).

Fraud pentagon merupakan pengembangan dari fraud triangle theory oleh Cressey (1953), kemudian fraud diamond theory yang dikembangkan oleh Wolf $\&$ hermanson (2004). Crowe, 2011 mengembangkan 
teori fraud tiangle dan fraud diamond dengan merubah risk factor fraud berupa capability menjadi competence yang memiliki makna istilah yang sama. Selain itu ada penambahan risk factor berupa arrogance (arogansi) (Siddiq, et al, 2017). Variabel-variabel dari Fraud pentagon ini tidak dapat begitu saja diteliti sehingga membutuhkan proksi variabel. Proksi yang dapat digunakan untuk penelitian ini antara lain Pressure yang diproksikan dengan financial stability, financial target, Personal Financial Needs, dan external pressure; Opportunity yang diproksikan dengan ineffective monitoring, nature of industry dan Quality of external auditor; Rationalization yang diproksikan dengan Change in Auditor dan Competence yang diproksikan dengan change of directors dan; Arrogance yang diproksikan dengan frequent number of CEO's pictures. Kelima faktor tersebut menjadi pemicu terjadinya Fraud.

Menurut peneliti topik penelitian ini penting dan menarik untuk diteliti secara lebih mendalam agar dapat mendeteksi kecurangan pelaporan keuangan yang diproksikan lewat Fraud Pentagon, penelitian sebelumnya mengenai fraud masih banyak didominasi oleh model fraud triangle dan model fraud diamond, peneliti tertarik untuk mengetahui dan menganalisis fraudulent financial reporting menggunkan analisis fraud pentagon yang dikemukakan oleh Crowe (2011).

\section{KAJIAN PUSTAKA DAN PENGEMBANGAN HIPOTESIS}

\section{Teori Keagenan (Agency Theory)}

Jensen dan Meckling (1976) menyatakan hubungan keagenan timbul karena adanya kontrak antara prinsipal dan agen dengan mendelegasikan beberapa wewenang pengambilan keputusan kepada agen. Fraudulent financial reporting bias terjadi karena ada celah-celah tertentu yang sengaja dimanfaatkan oleh agen (manager perusahaan) yang dalam hal ini agen telah mengetahui secara persis peluang tersebut dan tahu bagaimana cara menutupi agar tindakan kecurangan atau fraud tidak diketahui oleh principal (pemilik perusahaan).

\section{Fraud}

Fraud menurut the Association of Certified Fraud Examiners (ACFE) adalah perbuatan melawan hukum yang dilakukan secara sengaja dengan tujuan tertentu seperti manipulasi, memberikan laporan yang keliru atau bentuk perbuatan lain yang dilakukan oleh pihak pihak tertentu baik dari dalam organisasi maupun dari luar organisasi untuk mendapatkan keuntungan pribadi maupun kelompok tertentu yang secara langsung ataupun tidak langsung dapat merugikan pihak lain.

\section{Kecurangan Pelaporan Keuangan (Fraudulent Financial Reporting)}

Menurut The Association of Certified Fraud Examiners (ACFE, 2014) (dalam Tessa dan Harto,2016) sebagai berikut : "The deliberate misrepresentation of the financial condition of an enterprise accomplished through the intentional misstatement or omission of amounts or disclosures in the financial statements in order to deceive financial statement users." Yang dimaksudkan sebagai kekeliruan yang disengaja dari kondisi keuangan suatu perusahaan yang dilakukan melalui perbuatan salah saji yang disengaja atau kelalaian dari jumlah atau pengungkapan dalam laporan keuangan untuk menipu pengguna laporan keuangan.

\section{Teori Fraud Triangel}

Cressey (1953) dalam Skousen et al. (2008) memperkenalkan fraud triangel yang dapat digunakan untuk mendeteksi penyebab terjadinya kecurangan. Adapun tiga elemen yang menjadi penyebab terjadinya kecurangan (fraud) yaitu: Tekanan (pressure), Kesempatan (Opportunity), dan Rasionalisasi (Rationalization).

\section{Teori Fraud Diamond}

Fraud diamond merupakan suatu bentuk penyempurnaan dari teori fraud triangle oleh Cressey (1953). Elemen-elemen dari fraud diamond sebenarnya sama dengan elemen-elemen yang terdapat dalam fraud triangle tetapi pada fraud diamond ditambahkan elemen capability sebagai penyempurnanya. Capability sebagai elemen pembaharuan dari fraud triangle yang dikemukakan oleh Wolfe dan Hermanson mampu mencegah terjadinya fraud. Wolfe dan Hermanson (2004) berpendapat bahwa penipuan tidak akan terjadi tanpa orang yang tepat dengan 
kemampuan yang tepat untuk melaksanakan setiap detail dari penipuan.

\section{Teori Fraud Pentagon}

Teori terbaru yang mengupas lebih mendalam mengenai faktor-faktor pemicu fraud adalah teori fraud pentagon (Crowe's fraud pentagon theory). Teori ini dikemukakan oleh Crowe Howarth pada 2011. Teori fraud pentagon merupakan perluasan dari teori fraud triangle yang sebelumnya dikemukakan oleh Cressey, dalam teori ini menambahkan dua elemen fraud lainnya yaitu kompetensi (competence) dan arogansi (arrogance).

Kompetensi (competence) yang dipaparkan dalam teori fraud pentagon memiliki makna yang serupa dengan kapabilitas/kemampuan (capability) yang sebelumnya dijelaskan dalam teori fraud diamond oleh Wolfe dan Hermanson pada 2014. Menurut Crowe, arogansi adalah sikap superioritas atas hak yang dimiliki dan merasa bahwa kontrol internal atau kebijakan perusahaan tidak berlaku untuk dirinya (Tessa dan Harto,2016).

\section{Gambar 2.3}

\section{Fraud Pentagon}

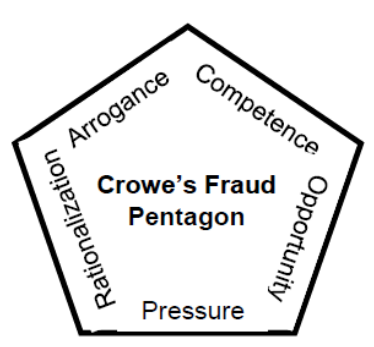

\section{Pengaruh Financial Stability dalam mendeteksi fraudulent financial reporting}

Variabel Pressure (Tekanan) yang pertama adalah stabilitas keuangan (financial stability). Financial stability merupakan suatu kondisi yang menggambarkan stabilitas keuangan perusahaan dalam posisi stabil (SAS No. 99). Keuangan perusahaan dapat dikatakan stabil dengan mengukur pertumbuhan keuangannya melalui penjualan perusahaan, nilai laba perusahaan per tahun dan pertumbuhan aset perusahaan (Siddiq, et al, 2017). Keadaan perusahaan yang tidak stabil akan menimbulkan tekanan untuk manajemen sebagai akibat dari kurang maksimalnya kinerja dalam memaksimalkan aset dan kurang berhasil dalam mengelola sumber dana investasi dengan efisien (Rahmono, et al, 2014).

$\begin{array}{llrr}\text { Menurut Statment of Auditing } & \text { Standard } \\ \text { (SAS) No.99, dijelaskan } & \text { bahwa manajer }\end{array}$ menghadapi tekanan untuk melakukan kecurangandan manipulasi laporan keuangan ketika stabilitas keuangan dan profitabilitas perusahaannya terancam kondisi ekonomi, industri, dan situasi lainnya. Penelitian yang dilakukan Sihombing (2014) menyatakan bahwa financial stability berpengaruh secara signfikan terhadap financial statement fraud. Berdasarkan penjelasan diatas, maka dapat diturunkan hipotesis :

$\mathrm{H}_{1} \quad$ : Financial Stability berpengaruh terhadap fraudulent financial reporting Pengaruh Financial Target dalam mendeteksi
fraudulent financial reporting

Variabel pressure (tekanan) yang kedua adalah target keuangan (financial target). Menurut SAS No.99 Financial Target merupakan suatu risiko akibat adanya tekanan yang kuat kepada manajemen dalam mencapai target keuangan yang didasarkan pada ketentuan manajemen atau direksi termasuk di dalamnya penentuan bonus dan insentif yang akan diterima oleh karyawan.

Financial target erat kaitannya dengan kinerja perusahaan, salah satu pengukuran untuk menilai tingkat laba yang diperoleh perusahaan atas usaha yang dikeluarkan adalah ROA (Return On Assets). Semakin tinggi ROA yang ditargetkan perusahaan, maka semakin rentan manajemen melakukan manipulasi laba yang menjadi salah satu bentuk kecurangan sehingga memiliki hubungan positif dengan kecurangan laporan keuangan.

Penelitian Putriasih, et al (2016) menemukan bahwa financial target merupakan bentuk dari kinerja perusahaan dengan indikator ROA dan mempengaruhi terjadinya financial statement fraud. Berdasarkan penjelasan diatas, maka dapat diturunkan hipotesis :

$\mathrm{H}_{2}$ : Financial Target berpengaruh terhadap fraudulent financial reporting 


\section{Pengaruh External Pressure dalam mendeteksi} fraudulent financial reporting

Variabel pressure (tekanan) yang ketiga adalah tekanan eksternal (external pressure) merupakan tekanan yang berlebihan bagi manajemen untuk memenuhi persyaratan atau harapan dari pihak ketiga. Tekanan eksternal diproksikan dengan menggunakan rasio leverage yaitu perbandingan antara total liabilitas dan total aset.

Apabila perusahaan memiliki leverage yang tinggi, berarti perusahaan tersebut dianggap memiliki hutang yang besar dan risiko kredit yang dimilikinya juga tinggi. Semakin tinggi risiko kredit, semakin besar tingkat kekhawatiran kreditor untuk memberikan pinjaman kepada perusahaan. Oleh karena itu, hal ini menjadi salah satu hal yang menjadi perhatian tersendiri bagi perusahaan dan memungkinkan menjadi salah satu penyebab dalam munculnya kecurangan pelaporan keuangan (Tessa dan Harto,2016).

Penelitian Yesiariani dan Rahayu (2016) menyatakan bahwa external pressure yang diproksikan dengan LEV berpengaruh positif signifikan terhadap resiko terjadinya financial statement fraud. Begitu pula penelitian yang dilakukan oleh Tessa dan Harto (2016), menyatakan bahwa external pressure berpengaruh signifikan dalam mendeteksi terjadinya fraudulent financial reporting. Berdasarkan penjelasan diatas, maka dapat diturunkan hipotesis :

$\mathrm{H}_{3} \quad$ : External Pressure berpengaruh terhadap fraudulent financial reporting

\section{Pengaruh Personal Financial Needs dalam mendeteksi fraudulent financial reporting}

Variabel tekanan (pressure) yang keempat adalah kebutuhan keuangan individu (personal financial need) merupakan suatu kondisi ketika keuangan perusahaan turut dipengaruhi oleh kondisi keuangan para eksekutif perusahaan (Skousen et al., 2009) dalam (Yesiariani dan Rahayu,2016). Ketidak jelasan pemisahan antara kepemilikan saham dengan kontrol perusahaan akan memicu manajer seenaknya dalam penggunaan dana perusahaan dalam memenuhi keinginan pribadi (Siddiq, et al, 2017).
Penelitian Yesiariani dan Rahayu (2016) menyatakan bahwa variabel personal financial need (OSHIP) tidak berpengaruh terhadap financial statement fraud, sedangkan penelitian Kusumaningrum dan Murtanto (2016) menyatakan bahwa personal financial needs berpengaruh negatif dalam mendeteksi kecurangan laporan keuangan. Penelitian lainnya adalah Skousen et,al (2009) yang menjelaskan bahwa persentase personal finansial need yang dikatagorikan pada institutional ownership (OSHIP) berpengaruh positif terhadap finansial statement fraud. Berdasarkan penjelasan diatas, maka dapat diturunkan hipotesis :

$\mathrm{H}_{4} \quad$ : Personal Financial Need berpengaruh terhadap fraudulent financial reporting

\section{Pengaruh Nature of Industry dalam mendeteksi fraudulent financial reporting}

Variabel kesempatan (opportunity) yang pertama yaitu sifat industri (nature of industry) merupakan keadaan ideal suatu perusahaan dalam industri. Keadaan tersebut diukur melalui akun piutang pada laporan keuangan. Pada laporan keuangan terdapat akun-akun tertentu yang besarnya saldo ditentukan oleh perusahaan berdasarkan suatu estimasi, misalnya akun piutang tak tertagih dan akun persediaan usang. Menurut Annisya, et al (2016) Penilaian estimasi seperti persediaan yang sudah usang dan piutang tak tertagih memungkinkan manajemen untuk melakukan manipulasi, seperti memanipulasi umur ekonomis aset. Dengan adanya penilaian subjektif dalam menentukan nilai dari akun tersebut, manajemen dapat menggunakan akun tersebut sebagai alat untuk melakukan financial statement fraud dalam penyusunan laporan keuangan. Nature of industry diukur menggunakan proksi rasio perubahan piutang usaha.

Hasil penelitian Sihombing (2014) menyatakan bahwa nature of industry berpengaruh positif terhadap kecurangan laporan keuangan. Berdasarkan penjelasan diatas, maka dapat diturunkan hipotesis :

$\mathrm{H}_{5} \quad$ : Nature of Industry berpengaruh terhadap fraudulent financial reporting

Pengaruh Ineffective Monitoring dalam mendeteksi fraudulent financial reporting 
Variabel kesempatan (opportunity) yang kedua yaitu ketidakefektian pengawasan (ineffective monitoring) merupakan lemahnya perusahaan dalam mengawasi jalannya kinerja perusaahn, dampak dari kelemahan pengawasan ini akan memberikan kesempatan terhadap agen perusahaan yaitu manajer berperilaku menyimpang dengan melakukan manajemen laba (Andayani, 2010) dalam (Yesiariani dan Rahayu,2016). Lemahnya pengawasan manajemen akan menimbulkan tindakan fraud dalam laporan keuangan. Pengawasan erat kaitannya dengan dewan komisaris. Proporsi dewan komisaris yang lebih besar dapat mencegah tindakan fraud dalam perusahaan (Siddiq, et al,2017).

Beasley, et al, (2002) dalam Siddiq, et al (2017) menjelaskan bahwa proporsi dewan komisaris indepeden dalam suatu perusahaan mempengaruhi terjadinya fraud di dalam perusahaan. BDOUT merupakan proksi untuk ineffective monitoring karena merupakan rasio terhadap proporsi dewan komisaris independen terhadap total dewan komisaris (Siddiq, et al, 2017).

Penelitian Putriasih, et al (2016) disimpulkan bahwa Ineffective monitoring dapat digunakan untuk mendeteksi atau berpengaruh terhadap Financial Statement Fraud. Berdasarkan penjelasan diatas, maka dapat diturunkan hipotesis :

$\mathrm{Ha}_{6} \quad$ : Ineffective monitoring berpengaruh terhadap fraudulent financial reporting

\section{Pengaruh quality of external auditor dalam mendeteksi fraudulent financial reporting}

Variabel kesempatan (opportunity) yang ketiga adalah kualitas auditor eksternal. Kualitas audit merupakan probabilitas seorang auditor dalam mendeteksi dan melaporkan hasil dari aktivitas yang diaudit audit (De Angelo,1981) dalam (Siddiq et al, 2017). Kualitas auditor eksternal dapat mempengaruhi dalam mendeteksi kecurangan laporan keuangan, maka dari itu dibutuhkan auditor eksternal yang memiliki keahlian dan kemampuan yang memadai dalam mengaudit laporan keuangan. Kualitas auditor eksternal ditentukan pada perbedaan pemilihan jasa audit dari kantor akuntan publik yang ditunjuk oleh perusahaan yaitu KAP yang tergabung dalam BIG4
(PWC, KPMG, Deloitte, Ernest\&Young) dan Non BIG4.

Menurut penelitian yang dilakukan oleh Lennox dan Pittman (2010) dalam (Sihombing, 2014) menyatakan bahwa auditor eksternal yang bekerja pada perusahaan audit besar "BIG 4" memiliki kemampuan lebih untuk mendeteksi fraud dibandingkan dengan perusahaan yang di audit oleh perusahaan audit non-BIG 4. Perusahaan yang diaudit oleh KAP "BIG4" maka peluang dalam mendeteksi terjadinya financial statement fraud akan lebih besar daripada perusahaan yang diaudit oleh KAP "NonBIG4", karena hasil audit oleh KAP BIG 4 dianggap lebih memiliki kemampuan dan keahlian untuk menghasilkan laporan keuangan yang lebih berkualitas. Berdasarkan penjelasan diatas, maka dapat diturunkan hipotesis :

$\mathrm{H}_{7} \quad$ : Quality of External Audit berpengaruh terhadap fraudulent financial reporting

\section{Pengaruh Change in Auditor dalam mendeteksi fraudulent financial reporting}

Variabel rasionalisasi (rationalization) yang pertama yaitu pergantian auditor (change in auditor). Dalam SAS No.99 (AICPA, 2002) menyatakan bahwa pengaruh adanya pergantian auditor dalam perusahaan dapat menjadi indikasi terjadinya kecurangan. Auditor yang lama mungkin lebih dapat mendeteksi segala kemungkinan kecurangan yang dilakukan oleh manajemen, baik itu secara langsung maupun tidak langsung. Namun, dengan adanya pergantian auditor, maka kemungkinan terjadinya kecurangan akan semakin meningkat (Yesiariani dan Rahayu, 2016). Berdasarkan penjelasan diatas, maka dapat diturunkan hipotesis :

$\mathrm{Ha}_{8} \quad$ : Change in Auditor berpengaruh terhadap fraudulent financial reporting

\section{Pengaruh Change of directors dalam mendeteksi fraudulent financial reporting}

Variabel Competence yang pertama yaitu change of directors. Competence artinya seberapa besar daya dan kapasitas dari seseorang itu melakukan Fraud di lingkungan perusahaan. Dalam penelitian ini 
akan digunakan perubahan direksi (change of directors) sebagai proksi dari competence. Pergantian direksi dapat menjadi suatu upaya perusahaan untuk memperbaiki kinerja direksi sebelumnya dengan melakukan perubahan susunan direksi ataupun perekrutan direksi baru yang dianggap lebih berkompeten. Adanya pergantian direksi juga dapat mengindikasikan suatu kepentingan politik tertentu untuk mengantikan jajaran direksi sebelumnya. Sementara disisi lain, pergantian direksi dianggap dapat mengurangi efektivitas dalam kinerja karena memerlukan waktu yang lebih untuk beradaptasi dengan culture direksi baru (Tessa dan Harto, 2016).

Putriasih, Herawati, dan Wahyuni (2016) menyatakan bahwa pergantian direksi berpengaruh dalam mendeteksi financial statement fraud. Demikian pula Siddiq, et al (2017) menyatakan bahwa change of directors berpengaruh terhadap financial statement fraud. Berdasarkan penjelasan diatas, maka dapat diturunkan hipotesis :

$\mathrm{Ha}_{9} \quad$ : Change of directors berpengaruh terhadap fraudulent financial reporting

\section{Pengaruh Frequent number of CEO's pictures dalam mendeteksi fraudulent financial reporting}

Variabel Arrogance yang diproksikan dengan Frequent number of CEO's pictures merupakan jumlah foto $\mathrm{CEO}$ yang terpampang pada laporan tahunan perusahaan. Banyaknya foto CEO yang terpampang dalam sebuah laporan tahunan perusahaan dapat merepresentasikan tingkat arogansi atau superioritas yang dimiliki CEO tersebut. Seorang CEO cenderung lebih ingin menunjukkan kepada semua orang akan status dan posisi yang dimilikinya dalam perusahaan karena mereka tidak ingin kehilangan status atau posisi tersebut (atau merasa tidak dianggap), hal ini sesuai dengan salah satu elemen yang dipaparkan oleh Crowe (2011) dalam Tessa dan Harto (2016). Arrogance dapat memicu terjadinya financial statement fraud dengan cara menggunakan dan memanfaatkan wewenang yang dimiliki. Control internal system apapun tidak bisa membatasi tindakan dan perilaku seorang CEO karena kekuasaan yang dimiliki (Siddiq, et al, 2017).

Penjelasan tersebut didukung oleh penelitian Siddiq et al (2017) menyatakan bahwa frequency numbers of CEO's pictures berpengaruh terhadap financial statement fraud. Begitu pula penelitian yang dilakukan oleh Tessa dan Harto (2016) yang menyatakan bahwa frequent number of CEO's pictures (CEOPIC) berpengaruh secara positif dan signifikan terhadap fraudulent financial reporting. Berdasarkan penjelasan diatas, maka dapat diturunkan hipotesis :

$\mathrm{Ha}_{10}$ : Frequent number of CEO's pictures berpengaruh terhadap fraudulent financial reporting

\section{METODE PENELITIAN}

\section{Variabel Dependen}

Variabel dependen yang digunakan dalam penelitian ini adalah fraudulent financial reporting yang diproksikan dengan penyajian kembali laporan keuangan (restatement). Menurut Salavei dan Moore (2005) dalam Tessa dan Harto (2016) menganggap bahwa penyajian kembali laporan keuangan atau financial statement restatement dapat memberikan sinyal atau tanda terhadap adanya kecurangan pelaporan keuangan yang dilakukan oleh suatu perusahaan.

Perusahaan yang dikategorikan melakukan penyajian kembali laporan keuangan (restatement) diakibatkan karena kesalahan mendasar, reklasifikasi, adanya transaksi dengan pihak-pihak istimewa, dan penyajian kembali yang bukan disebabkan karena perubahan kebijakan dan estimasi akuntansi akibat konvergensi/penerapan Pernyataan Standar Akuntansi Keuangan (PSAK)-International Financial Reporting Standard (IFRS) (Tessa dan Harto, 2016). Penyajian kembali (restatement) laporan keuangan diukur menggunakan variabel dummy, dimana kode 1 untuk perusahaan yang melakukan penyajian kembali laporan keuangan, dan 0 jika tidak.

\section{Variabel Independen}

Varibel independen yang digunakan dalam penelitian ini adalah Financial stability, Financial target, External pressure, Personal financial needs, Nature of industry, Innefective monitoring, Quality of External Auditor, Change in Auditor, Change of Directors, Frequent Number of CEO's Pictures. Pengukuran variabel independen dijelaskan dalam table berikut : 


\begin{tabular}{|c|c|}
\hline Nama Variabel & Pengukuran \\
\hline Financial Stability & $\begin{array}{c}\text { ACHANGE }= \\
\frac{\left(\text { Total Asset }_{\mathrm{t}}-\text { Total }\right.}{\left.\text { Asset }_{\mathrm{t}}-1\right)} \\
\text { Total Asset }_{\mathrm{t}}\end{array}$ \\
\hline Financial Target & $\begin{array}{c}\mathrm{ROA}=\frac{\text { Laba setelah }}{\underline{\text { pajak }}} \\
\text { Total Asset }\end{array}$ \\
\hline External pressure & $\begin{array}{r}\mathrm{LEV}=\underline{\text { Total Hutang }} \\
\text { Total Asset }\end{array}$ \\
\hline Personal financial needs & $\begin{array}{l}\text { Variabel dummy, kode } 1 \\
\text { (satu) untuk perusahaan } \\
\text { yang terdapat kepemilikan } \\
\text { saham oleh orang dalam, } \\
\text { kode } 0 \text { (nol) untuk yang } \\
\text { tidak terdapat kepemilikan } \\
\text { saham oleh orang dalam. }\end{array}$ \\
\hline Nature of Industry & $\begin{array}{c}\text { RECEIVABLE }=\underline{\text { Piutang }} \underline{\underline{t}} \\
\text { Piutang }_{t 1}\end{array}$ \\
\hline & Penjualan $_{t} \quad$ Penjualan $_{t-1}$ \\
\hline Innefective monitoring & $\begin{array}{c}\text { BDOUT }=\quad \underline{\text { Total }} \\
\text { ko isaris independen } \\
\text { Total dewan } \\
\text { komisaris }\end{array}$ \\
\hline $\begin{array}{l}\text { Quality of External } \\
\text { Auditor }\end{array}$ & $\begin{array}{l}\text { variabel dummy, kode } 1 \\
\text { (satu) jika menggunakan } \\
\text { jasa audit KAP BIG } 4 \text {, dan } \\
\text { kode } 0 \text { (nol) jika tidak } \\
\text { menggunakan KAP BIG } 4\end{array}$ \\
\hline Change in Auditor & $\begin{array}{l}\text { variabel } \\
\text { pergantian auditor diberi } \\
\text { kode } 1 \text { (satu) dan kode } 0 \\
\text { (nol) untuk perusahaan } \\
\text { yang tidak mengganti } \\
\text { auditornya selama masa }\end{array}$ \\
\hline
\end{tabular}

\begin{tabular}{|l|l|}
\hline & penelitian. \\
\hline Change of Directors & $\begin{array}{l}\text { Variabel dummy, } \\
\text { pergantian direksi diberi } \\
\text { kode 1 dan kode 0 untuk } \\
\text { perusahaan yang tidak } \\
\text { mengganti direksinya } \\
\text { selama masa penelitian. }\end{array}$ \\
\hline $\begin{array}{l}\text { Frequent number of } \\
\text { CEO's pictures }\end{array}$ & $\begin{array}{l}\text { CEOPIC = total foto CEO } \\
\text { yang terpampang dalam } \\
\text { sebuah laporan tahunan. }\end{array}$ \\
\hline
\end{tabular}

\section{Populasi dan Sampel}

Populasi dalam penelitian ini adalah seluruh perusahaan manufaktur yang telah listed di Bursa Efek Indonesia selama periode 2014-2016. Pengambilan sampel dalam penelitian ini menggunakan teknik purposive sampling, yaitu teknik penentuan sampel dengan pertimbangan tertentu. dalam penelitian pengambilan sampel ditentukan dengan kriteria sebagai berikut :

1. Perusahaan manufaktur yang go public atau terdaftar di Bursa Efek Indonesia (BEI) secara berturut-turut selama periode 2014-2016;

2. Perusahaan mempublikasikan laporan keuangan

- tahunan secara lengkap dalam website perusahaan atau website BEI selama periode 2014-2016 yang dinyatakan dalam rupiah (Rp);

3. Perusahaan yang tidak delisting dari BEI selama periode pengamatan (2014-2016);

4. Perusahaan yang mempublikasikan laporan keuangan tahunan secara lengkap sesuai dengan data yang diperlukan dalam penelitian.

Metode Analisis

Alat analisis yang digunakan dalam penelitian ini adalah analisis regresi logistik (logistic regression).

\section{Analisis Statistik Deskriptif}

Analisis Statistik digunakan untuk memberikan diskripsi atas variabel-variabel penelitian yang meliputi financial stability, financial target, personal financial needs, external pressure, nature of industry, ineffective monitoting, quality of external auditor, change in auditor, change of directors, frequent number of ceo pic terhadap fraudulent financial reporting. Analisis statistik deskriptif meliputi jumlah 
sampel, nilai minimum, nilai maksimum, nilai rata-rata (mean), dan standar deviasi.

\section{Regresi Logistik}

Logistic regression (regresi logistik) adalah analisis yang digunakan untuk menguji apakah probabilitas terjadinya variabel terikat dapat diprediksi dengan variabel bebasnya (Ghozali, 2011). Berikut Langkah pengujian hipotesis dengan menggunakan logistic regression (regresi logistik).

\section{a. Menilai Keseluruhan Model (Overall Model Fit)}

Langkah pertama adalah menilai keseluruhan model terhadap data. Pengujian ini dilakukan untuk menilai model yang dihipoteiskan fit dengan data atau tidak. Pengujian dilakukan dengan membandingkan nilai antara -2 log likelihood pada awal (blok number $=$ 0) dengan nilai -2 log likelihood pada akhir (blok number $=1$ ). Pengurangan nilai antara $-2 L L$ awal (initial -2LL function) dengan nilai $-2 L L$ pada langkah awal berikutnya menunjukkan bahwa variabel yang dihipotesiskan fit dengan data. Hal ini karena log likelihood pada regresi logistik mirip dengan "sum of square error" pada model regresi sehingga penurunan log likelihood menunjukkan model regresi semakin baik.

\section{b. Menganalisis Koefisien Determinasi (Nagelkerke R Square)}

Koefisien determinasi digunakan untuk mengetahui seberapa besar variabilitas variabelvariabel independen mampu memperjelas variabilitas variabel dependen. Besarnya nilai koefisien determinasi pada model regresi logistic ditunjukkan oleh nilai Nagerkelke $R$ Square. Nilai Nagerkelke $R$ Squaredapat diinterpretasikan seperti nilai $R$ Square pada regresi berganda. Nilai ini dapat dengan cara membagi nilai Cox \& Snell $R$ Square dengan nilai maksimumnya.

\section{c. Menilai Kelayakan Model Regresi}

Kelayakan model regresi dinilai dengan menggunakan Hosmer and Lemeshow's Goodness of Fit Test. Model ini untuk menguji hipotesis nol bahwa data empiris sesuai dengan model atau dapat dikatakan fit. Jika nilai Hosmer and Lemeshow Goodness of Fit sama dengan atau kurang dari 0,05, maka hipotesis nol ditolak yang berarti ada perbedaan signifikan antara model dengan nilai observasinya yang mana tidak baik karena model tidak dapat memprediksi nilai observasinya. Kemudian jika Hosmer and Lemeshow Goodness of Fit lebih besar dari 0,05 maka artinya hipotesis nol dapat diterima yang berarti model mampu memprediksi nilai observasinya atau cocok dengan data observasi.

\section{d. Uji Wald}

Dalam regresi logistik uji Wald digunakan untuk menguji ada tidaknya pengaruh dari variabel bebas terhadap variabel terikat secara parsial dengan cara membandingkan nilai statistik Wald dengan nilai pembanding Chi square pada derajat bebas $(\mathrm{db})=1$ pada alpha $5 \%$, atau dengan membandingkan nilai signifikan (p-value) dengan alpha sebesar 5\% dimana p-value yang lebih kecil dari alpha menunjukkan bahwa hipotesis diterima atau terdapat pengaruh yang signifikan dari variabel bebas terhadap variabel terikat secara parsial.

\section{e. Model Regresi Logistik yang Terbentuk}

Analisis yang digunakan dalam penelitian ini adalah analisis logistic regression (regresi logistik), yaitu dengan melihat pengaruh financial stability, financial target, personal financial needs, external pressure, nature of industry, ineffective monitoting, quality of external auditor, change in auditor, competence, frequent number of ceo pictures terhadap fraudulent financial reporting pada perusahaan manufaktur yang listed di Bursa Efek Indonesia tahun 2014-2016. Berikut model regresi logistik dalam penelitian ini :

\section{FFR $=$ BO + B1ACHANGE + B2ROA + B3LEV + B4OSHIP + B5RECEIVABLE + B6BDOUT + B7BIG + B8CPA + B9DCHANGE + B10CEOPIC + gi}

Keterangan:

ß0 : Koefisien regresi konstanta

$ß 1,2,3,4,5,6,7,8,9,10$ : Koefisien regresi masing-masing proksi

FFR : Variabel dummy, kode 1 untuk perusahaan yang melakukan penyajian kembali laporan keuangan, kode 0 untuk yang tidak. ACHANGE : Rasio perubahan total aset 
ROA : Return on assets

LEV : Rasio total kewajiban per total asset

OSHIP : Rasio komposisi saham yang dimiliki manajemen

RECEIVABLE : Rasio perubahan piutang usaha

BDOUT : Rasio dewan komisaris independen

BIG : Kualitas Auditor Eksternal

CPA : Pergantian auditor independen

DCHANGE : Pergantian direksi

CEOPIC : jumlah foto CEO yang terdapat dalam sebuah laporan keuangan

$\varepsilon$ : error

\section{HASIL DAN PEMBAHASAN}

Populasi dalam penelitian ini adalah seluruh perusahaan manufaktur yang terdaftar di Bursa Efek Indonesia (BEI) periode tahun 2014-2016 yang diperoleh melalui akses langsung dari website Indonesia Stock Exchange (www.idx.co.id). Dari populasi tersebut diambil sampel sesuai dengan kriteria hasil pemilihan sampel dengan menggunakan metode purposive sampling. Proses pengambilan sampel dapat dilihat pada tabel IV. 1.

Tabel 4.1

\section{Kriteria Pengambilan Sampel}

\begin{tabular}{l}
\hline \multicolumn{1}{c}{ Kriteria } \\
\hline Perusahaan manufaktur yang terdaftar \\
di Bursa Efek Indonesia selama tahun \\
2014-2016. \\
1. $\quad$ Perusahaan manufaktur yang \\
tidak menerbitkan laporan \\
keuangan tahunan secara \\
berturut-turut tahun 2014-2016. \\
Perusahaan manufaktur yang \\
tidak menerbitkan laporan \\
keuangan secara lengkap dan \\
tidak dinyatakan dalam mata \\
uang Rupiah
\end{tabular}

3. Perusahaan manufaktur yang delisting selama tahun

\section{Jumlah}

144

pengamatan

4. Perusahaan manufaktur yang tidak memiliki data lengkap untuk penelitian

Sampel penelitian 84

Total Sampel Penelitian ( $44 \times 3$ tahun) 252

Sumber: Hasil Analisis Data, 2018

Berdasarkan kriteria yang telah ditetapkan dengan metode purposive sampling diperoleh jumlah sampel sebanyak 84 perusahaan per tahun. Pada penelitian ini data disusun secara time series, jadi jumlah sampel yang diperoleh sebanyak 252 sampel (84 perusahaan $\mathrm{x}$ 3 tahun).

\section{Statistik Deskriptif}

Berikut analisis statistik deskriptif terhadap variabel penelitian dapat dilihat pada tabel 4.2.

Tabel 4.2

Analisis Statistik Deskriptif

\begin{tabular}{lccrrr}
\hline \multicolumn{1}{c}{ Variabel } & N & Minimum & Maximum Mean & $\begin{array}{c}\text { Std. } \\
\text { Deviation }\end{array}$ \\
\hline ACHANGE & 252 & -0.143 & 0.803 & 0.116 & 0.135829 \\
& & & & 15 & \\
ROA & 252 & 0.066 & 0.839 & 0.387 & 0.201885 \\
& & & 02 & \\
LEV & 252 & 0.071 & 0.819 & 0.48 & 0.502 \\
OSHIP & 252 & 0 & 1 & 0.476 & 0.505487 \\
& & & & 19 & \\
RECEIVABL & 252 & -0.249 & 0.157 & 0.001 & 0.039377 \\
E & & & & 07 & \\
BDOUT & 252 & 0.167 & 0.800 & 0.420 & 0.114560 \\
& & & & 13 & \\
BIG & 252 & 0 & 1 & 0.48 & 0.501 \\
CPA & 252 & 0 & 1 & 0.50 & 0.502 \\
DCHANGE & 252 & 0 & 1 & 0.45 & 0.500 \\
CEOPIC & 252 & 0 & 31 & 7.42 & 6.902 \\
\hline \multicolumn{5}{c}{ Sumber: Hasil Analisis data, 2018 } \\
\end{tabular}


Berdasarkan hasil statistik deskriptif di atas dapat dijelaskan bahwa:

1. Variable financial stability (ACHANGE) diukur dengan analisis statistik dekriptif memiliki nilai maksimum sebesar 0,803 , nilai minimum sebesar $-0,143$ nilai standar devisiasi sebesar 0,1358 dan memiliki nilai rata- rata (mean) sebesar 0,11615, berarti perusahaan manufaktur yang terdaftar di BEI periode 2014-2016 yang menjadi sampel penelitian memiliki kondisi keuangan yang stabil.

2. Variable financial target (ROA) diukur dengan analisis statistik dekriptif memiliki nilai maksimum sebesar 0,839 , nilai minimum sebesar 0,066 nilai standar devisiasi sebesar 0,2019 dan memiliki nilai rata- rata (mean) sebesar 0,38702, berarti sebagian besar perusahaan manufaktur yang terdaftar di BEI periode 2014-2016 memiliki financial target cukup rendah.

3. Varibel external pressure (LEV) diukur dengan menggunakan analisis statistik deskriptif memiliki nilai maksimum sebesar 0,819 , nilai minimum sebesar 0,071 , nilai standar devisiasi sebesar 0,502 dan memiliki nilai rata- rata (mean) sebesar 0,480, dengan demikian berdasarkan pada nilai rata-rata, sebagian besar perusahaan manufaktur yang terdaftar di BEI periode 20142016 memiliki external pressure dari pihak ketiga yang tidak terlalu tinggi.

4. Variabel personal financial need (OSHIP) diukur dengan analisis statistik deskriptif memiliki nilai maksimum sebesar 1 , nilai minimum 0 , dan nilai standar devisiasi sebesar 0,5055 dan memiliki nilai rata-rata (mean) sebesar 0,4762 dengan demikian berdasarkan pada nilai rata-rata, sebagian besar perusahaan manufaktur yang terdaftar di BEI periode 2014-2016 memiliki personal financial need yang cenderung rendah.

5. Variabel nature of industry (RECEIVABLE) diukur dengan analisis deskriptif statistik memiliki nilai maksimum sebesar 0,157 , memiliki nilai minimum sebesar $-0,249$, nilai standar devisiasi sebesar 0,0394 dan memiliki nilai rata-rata (mean) sebesar 0,001 dengan demikian berdasarkan pada nilai rata-rata, sebagian besar perusahaan manufaktur yang terdaftar di BEI periode 2014-2016 memiliki nature of industry yang baik.
6. Variabel innefective monitoring (BDOUT) diukur dengan analisis statistik deskriptif memiliki nilai maksimum sebesar 0,800 , memiliki nilai minimum sebesar 0,167 , nilai standar devisiasi sebesar 0,1146 dan memiliki nilai rata- rata (mean) sebesar 0,4201 dengan demikian berdasarkan pada nilai rata-rata, sebagian besar perusahaan manufaktur yang terdaftar di BEI periode 2014-2016 yang menjadi sampel penelitian memiliki innefective monitoring yang baik.

7. Variabel quality of external auditor (BIG) diukur dengan analisis statistic deskriptif memiliki nilai maksimum sebesar 1 , nilai minimum sebesar 0 , nilai standar devisiasi sebesar 0,501 dan memiliki nilai rata- rata (mean) sebesar 0,48 dengan demikian berdasarkan pada nilai rata-rata, sebagian besar perusahaan manufaktur yang terdaftar di BEI periode 2014-2016 yang menjadi sampel penelitian menggunakan auditor Non Big Four.

8. Variabel change in auditor (CPA) diukur dengan analisis statistic deskriptif memiliki nilai maksimum sebesar 1 , nilai minimum sebesar 0 , nilai standar devisiasi sebesar 0,502 dan memiliki nilai rata- rata (mean) sebesar 0,50 dengan demikian berdasarkan pada nilai rata-rata, sebagian besar perusahaan manufaktur yang terdaftar di BEI periode 2014-2016 yang menjadi sampel penelitian jarang melakukan pergantian auditor.

9. Variabel change of directors (DCHANGE) diukur dengan analisis statistic deskriptif memiliki nilai maksimum sebesar 1 , nilai minimum sebesar 0 , nilai standar devisiasi sebesar 0,500 dan memiliki nilai rata- rata (mean) sebesar 0,45 dengan demikian berdasarkan pada nilai rata-rata, sebagian besar perusahaan manufaktur yang terdaftar di BEI periode 20142016 yang menjadi sampel penelitian jarang melakukan pergantian direksi.

10. Variabel frequent number of CEO's pictures (CEOPIC) diukur dengan analisis statistic deskriptif memiliki nilai maksimum sebesar 31, nilai minimum sebesar 0 , nilai standar devisiasi sebesar 6,902 dan memiliki nilai rata- rata (mean) sebesar 7,42 dengan demikian berdasarkan pada nilai rata-rata, sebagian besar perusahaan manufaktur yang terdaftar di BEI periode 2014- 
2016 yang menjadi sampel penelitian memajang semua foto direksi yang sedang menjabat.

\section{Pembahasan Hasil Penelitian}

Hasil pengujian kelayakan keseluruhan model (overall fit model test) perbandingan antara nilai angka awal -2 log Likelihood Block Number $=0$ adalah 341,624, sedangkan angka -2 log Likelihood Block Number $=1$ adalah 328,487. Dari model tersebut ternyata overall model fit pada $-2 \log$ Likelihood Block Number $=0$ menunjukkan adanya penurunan pada -2 $\log$ Likelihood Block Number $=1$. Penurunan $-2 \log$ Likelihood ini menunjukkan model regresi yang lebih baik atau dengan kata lain model yang dihipotesiskan fit dengan data.

Koefisien Determinasi memberikan ni] Nagel Karke $R$ Square sebesar 0,068. Hal ini bera Ste bahwa $6,8 \%$ variabel dependen fraudulent financl $\mathrm{p}{ }^{1}$ reporting dapat dijelaskan oleh variasi variat independent financial stability, financial targ external pressure, personal financial need, nature industry, innefective monitoring, quality of extern auditors, change in auditor, change directors, frequent number of CEO's picturs Sedangkan sisanya 93,2\% dijelaskan oleh variabel la yang tidak digunakan dalam penelitian ini.

Berdasarkan nilai dari pengujian Hosmer ai Lemeshow adalah sebesar 0,513. Dari hasil tersebı maka dapat dikatakan bahwa $H_{0}$ diterima, yang ma hal tersebut dikarenakan nilai signifikasi yal diperoleh jauh lebih besar daripada 0,05, sehing. dapat disimpulkan bahwa model mampu mempredik nilai observasinya atau dapat dikatakan pula moc dapat diterima karena sesuai dengan ni observasinya.

Matrik klasifikasi menunjukkan kekuatan prediksi dari model regresi untuk memprediksi kemungkinan terjadinya fraudulent financial reporting yang dilakukan oleh perusahaan. Kekuatan prediksi dari model regresi untuk memprediksi kemungkinan perusahaan melakukan fraudulent financial reporting sebesar $87,2 \%$. Hal ini menunjukkan bahwa dengan menggunakan model regresi yang digunakan terdapat sebanyak 129 sampel $(87,2 \%)$ yang diprediksi akan melakukan fraudulent financial reporting dari total
148 sampel yang melakukan fraudulent financial reporting. Kekuatan prediksi model sampel tidak melakukan fraudulent financial reporting adalah sebesar $27,9 \%$, yang berarti bahwa dengan model regresi yang digunakan ada sebanyak 75 sampel $(27,9 \%)$ yang diprediksi tidak melakukan fraudulent financial reporting dari total 104 sampel yang tidak melakukan kecurangan pelaporan keuangan (fraudulent financial reporting).

\section{Pengujian Hipotesis}

Tabel 4.3

Uji Hipoptesis

\begin{tabular}{|c|c|c|c|c|c|c|}
\hline & B & S.E. & Wald & df & Sig. & $\operatorname{Exp}(B)$ \\
\hline ACHANGE & 0,346 & 0,964 & 0,128 & 1 & 0,720 & 1,413 \\
\hline ROA & $\begin{array}{r}- \\
4,164\end{array}$ & 1,563 & 7,100 & 1 & 0,008 & 0,016 \\
\hline LEV & 0,109 & 0,471 & 0,054 & 1 & 0,816 & 0,896 \\
\hline OSHIP & - & 0,289 & 0,075 & 1 & 0,784 & 0,924 \\
\hline $\begin{array}{l}\text { RECEIVAB } \\
\text { LE }\end{array}$ & 0,568 & 1,619 & 0,123 & 1 & 0,726 & 1,764 \\
\hline BDOUT & 0,905 & 1,400 & 0,417 & 1 & 0,518 & 2,471 \\
\hline BIG & - & 0,315 & 0,044 & 1 & 0,833 & 0,936 \\
\hline $\mathrm{CPA}$ & 0,177 & 0,375 & 0,223 & 1 & 0,637 & 0,838 \\
\hline DCHANGE & 0,168 & 0,289 & 0,337 & 1 & 0,561 & 0,845 \\
\hline CEOPIC & 0,013 & 0,014 & 0,822 & 1 & 0,364 & 0,987 \\
\hline Constant & 0,581 & 0,637 & 0,832 & 1 & 0,362 & 1,788 \\
\hline
\end{tabular}

Sumber: Hasil Analisis Data 2018

Adapun model yang dihasilkan dari pengujian terhadap model regresi adalah sebagai berikut :

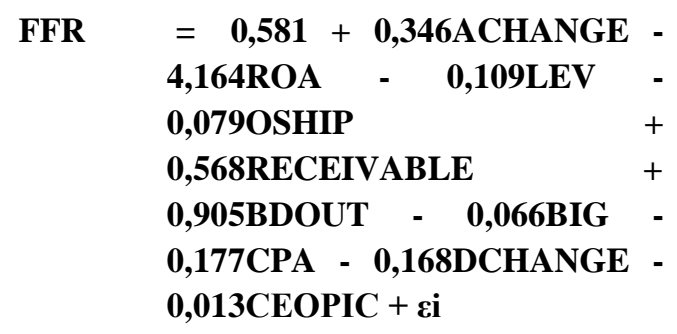


Pengujian hipotesis dilakukan dengan cara membandingkan antara tingkat signifikansi (sig) dengan tingkat kesalahan $(\alpha)=5 \%$ atau 0,05 .

\section{Financial Stability Tidak Berpengaruh Terhadap Fraudulent Financial Reporting.}

Variabel financial stability (ACHANGE) menunjukkan koefisiensi regresi sebesar 0,346 dengan tingkat signifikasi sebesar 0,720 lebih dari $\alpha=0,05$. Tingkat signifikasi lebih dari 0,05, maka hipotesis ke-1 ditolak. Penelitian ini membuktikan bahwa financial stability atau stabilitas keuangan tidak berpengaruh terhadap terjadinya fraudulent financial reporting. Hal ini dikarenakan ketika kondisi keuangan sedang tidak stabil atau terganggu, para manajer di perusahaan sampel belum tentu melakukan manipulasi laporan keuangan karena hal tersebut justru memperparah kondisi keuangan dimasa mendatang serta kemungkinan pada perusahaan sampel mempunyai tingkat pengawasan yang baik oleh dewan komisaris sehingga ketika para manajer menghadapi tekanan akibat kondisi keuangan yang terancam tidak mempengaruhi terjadinya fraudulent financial reporting.

Hasil penelitian ini mendukung penelitian yang dilakukan Yesiariani dan Rahayu (2016), serta Ulfah, et al (2017), namun tidak mendukung hasil penelitian Tessa dan Harto (2016), serta Siddiq, et al (2017).

\section{Financial Target Berpengaruh Terhadap Fraudulent Financial Reporting}

Variabel financial targets (ROA) menunjukkan koefisiensi regresi sebesar $-4,164$ dengan tingkat signifikasi sebesar 0,008 kurang dari $\alpha=0,05$. Tingkat signifikasi kurang dari 0,05 , maka hipotesis ke-2 diterima. Penelitian ini membuktikan bahwa financial target atau target keuangan berpengaruh terhadap terjadinya fraudulent financial reporting.

Financial target diukur menggunakan rasio ROA yaitu perbandingan laba dengan jumlah aktiva, dimana rasio ROA merupakan rasio yang menunjukkan seberapa besar return yang dihasilkan atas penggunaan aset perusahaan. ROA sering digunakan untuk menilai kinerja manajer dalam menentukan bonus, kenaikan upah, dan lain-lain (Putriasih, et al, 2016). Target yang dimiliki manajer perusahaan yang terlalu tinggi cenderung membuat manajer akan lebih ambisius, sehingga apapun cara akan ditempuh untuk mendapatkan target yang seharusnya. Jika semakin rendah nilai ROA mengindikasikan semakin rendah pula laba yang dihasilkan sehingga kinerja perusahaan terkesan buruk, sehingga kemungkinan terjadinya fraudulent financial reporting cukup tinggi.

Hasil penelitian ini mendukung penelitian yang dilakukan Hanifa dan Laksito (2015), Putriasih, et al (2016) serta dan Kusumaningrum dan Murtanto (2016), namun tidak mendukung hasil penelitian Tessa dan Harto (2016), serta Sihombing dan Rahardjo (2014).

\section{External Pressure Tidak Berpengaruh Terhadap Fraudulent Financial Reporting. \\ Variabel External pressure (LEV)} menunjukkan koefisiensi regresi sebesar $-0,109$ dengan tingkat signifikasi sebesar 0,816 lebih dari $\alpha=$ 0,05 . Tingkat signifikasi lebih dari 0,05 , maka hipotesis ke-3 ditolak. Penelitian ini membuktikan bahwa external pressure tidak berpengaruh terhadap terjadinya fraudulent financial reporting.

Banyaknya tekanan dari pihak ketiga yang diberikan kepada manajer perusahaan, biasanya akan cenderung mengakibatkan adanya tindakan kecurangan, namun semua itu belum tentu dilakukan oleh manajer perusahaan untuk menangani tingginya tekannan dari pihak ketiga. Manajer bisa saja mempunyai berbagai rencana dan strategi yang sesuai dengan standar akuntansi dalam penyusunan keuangan bisa digunakan untuk mencapai tujuan pihak ketiga, sehingga adanya tekanan yang tinggi dari pihak ketiga tidak membuat manajer melakukan tindakan kecurangan pada laporan keuangan perusahaan.

Hasil penelitian ini mendukung penelitian yang dilakukan Ulfah, et al (2017) serta Annisya, et al (2016), namun tidak mendukung hasil penelitian Tessa dan Harto (2016) serta Yesiariani dan Rahayu (2016).

\section{Personal Financial Needs Tidak Berpengaruh Terhadap Fraudulent Financial Reporting. \\ Variabel personal financial needs (OSHIP) menunjukkan koefisiensi regresi sebesar $-0,079$ dengan tingkat signifikasi sebesar 0,784 lebih dari $\alpha=$ 0,05 . Tingkat signifikasi lebih dari 0,05 , maka}


hipotesis ke-4 ditolak. Penelitian ini membuktikan bahwa personal financial needs tidak berpengaruh terhadap terjadinya fraudulent financial reporting.

Hal ini kemungkinan dikarenakan masih rendahnya rata-rata kepemilikan saham dalam perusahaan sampel. Kepemilikan saham yang rendah mengindikasikan bahwa pada perusahaan sampel telah terjadi pemisahan yang jelas antara pemegang saham sebagai pemilik yang mengontrol jalannya perusahaan dan manajer sebagai pengelola perusahaan. Adanya pemisahan pemisahan yang jelas menyebabkan manajer tidak mempunyai kemampuan yang cukup untuk melakukan kecurangan laporan keuangan (Tiffani, 2015 dalam Yesiariani dan Rahayu, 2016).

Hasil penelitian ini mendukung hasil penelitian yang dilakukan oleh Tessa dan Harto (2016) serta Yesiariani dan Rahayu (2016), namun tidak mendukung hasil penelitian Saputra dan Kesumaningrum (2017).

5. Nature of Industry Tidak Berpengaruh Terhadap Flaudulent Financial Reporting Variabel nature of industry (RECEIVABLE) menunjukkan koefisiensi regresi sebesar 0,568 dengan tingkat signifikasi sebesar 0,726 lebih dari $\alpha=0,05$. Tingkat signifikasi lebih dari 0,05, maka hipotesis ke-5 ditolak. Penelitian ini membuktikan bahwa nature of industry tidak berpengaruh terhadap terjadinya fraudulent financial reporting.

Hal ini dikarenakan nilai rata-rata perubahan piutang perusahaan dari tahun sebelumnya tidak berpengaruh terhadap perputaran kas perusahaan. Banyaknya piutang usaha yang dimiliki perusahaan tidak mengurangi jumlah kas yang dapat digunakan perusahaan untuk kegiatan operasionalnya sehingga rasio perubahan dalam piutang usaha tidak memicu manajer untuk melakukan kecurangan laporan keuangan (Yesiariani dan Rahayu, 2016).

Hasil penelitian ini mendukung hasil penelitian yang dilakukan oleh Yesiariani dan Rahayu (2016) serta Annisya, et al (2016), namun tidak mendukung hasil penelitian Sihombing dan Rahardjo (2014).

\section{Ineffective Monitoring Tidak Berpengaruh Terhadap Flaudulent Financial Reporting}

Variabel ineffective monitoring (BDOUT) menunjukkan koefisiensi regresi sebesar 0,905 dengan tingkat signifikasi sebesar 0,518 lebih dari $\alpha=0,05$. Tingkat signifikasi lebih dari 0,05, maka hipotesis ke-6 ditolak. Penelitian ini membuktikan bahwa ineffective monitoring tidak berpengaruh terhadap terjadinya fraudulent financial reporting.

Hal ini dikarenakan fraud dapat diminimalkan salah satunya dengan pengawasan yang baik. Dengan adanya dewan komisaris independen pengawasan operasional perusahaan akan dilakukan secara objektif dan independen sera jauh dari intervensi oleh pihapihak tertentu, sehingga tidak memicu manajer untuk melakukan kecurangan laporan keuangan.

Hasil penelitian ini mendukung penelitian yang dilakukan oleh Sihombing dan Rahardjo (2014), Tessa dan Harto (2016), serta Yesiariani dan Rahayu (2016), namun tidak mendukung hasil penelitian yang dilakukan oleh Putriasih, et al (2016)

\section{Quality of External Auditor Tidak Berpengaruh Terhadap Flaudulent Financial Reporting}

Variabel quality of external auditor (BIG) menunjukkan koefisiensi regresi sebesar -0,066 dengan tingkat signifikasi sebesar 0,833 lebih dari $\alpha=$ 0,05 . Tingkat signifikasi lebih dari 0,05 , maka hipotesis ke-7 ditolak. Penelitian ini membuktikan bahwa quality of external auditor tidak berpengaruh terhadap terjadinya fraudulent financial reporting. Hal ini dikarenakan, peran auditor eksternal baik KAP BIG-4 maupun KAP Non BIG-4 memiliki peranan yang sama dalam melakukan audit atas laporan keuangan serta menentukan kekeliruan dan kemungkinan yang menjadi penyebab laporan keuangan berisi salah saji material berdasarkan pada standar akuntansi yang berlaku umum. Sehingga kualitas auditor eksternal tidak mempengaruhi dalam kemungkinan terjadinya fraudulent financial reporting.

Hasil penelitian ini mendukung penelitian yang dilakukan oleh Tessa dan Harto (2016) serta Hanifa dan Laksito (2015). 
8. Change in Auditor Tidak Berpengaruh Terhadap Flaudulent Financial Reporting

Variabel change in auditor (CPA) menunjukkan koefisiensi regresi sebesar $-0,177$ dengan tingkat signifikasi sebesar 0,637 lebih dari $\alpha=$ 0,05 . Tingkat signifikasi lebih dari 0,05 , maka hipotesis ke-8 ditolak. Penelitian ini membuktikan bahwa quality of change in auditor tidak berpengaruh terhadap terjadinya fraudulent financial reporting.

Hal ini dikarenakan kemungkinan perusahaan melakukan pergantian auditor bukan karena ingin mengurangi pendektesian laporan keuangan oleh auditor lama, tetapi dikarenakan perusahaan menaati Peraturan Pemerintah Republik Indonesia Nomor 20 Tahun 2015 pasal 11 ayat 1 yang menyatakan bahwa pemberian jasa audit atas laporan keuangan terhadap suatu entitas oleh seorang Akuntan Publik dibatasi paling lama 5 (lima) tahun buku berturut-turut (Yesiariani dan Rahayu, 2016). Selain ini pergantian auditor mungkin dikarenakan perusahaan kurang puas terhadap kinerja auditor eksternal terdahulu.

Hasil penelitian ini mendukung penelitian yang dilakukan oleh Sihombing dan Rahardjo (2014), Tessa dan Harto (2016), serta Yesiariani dan Rahayu (2016), namun tidak mendukung hasil penelitian yang dilakukan oleh Ulfah et,al (2017)

\section{Change of Directors Tidak Berpengaruh Terhadap Flaudulent Financial Reporting}

Variabel change of directors (DCHANGE) menunjukkan koefisiensi regresi sebesar $-0,168$ dengan tingkat signifikasi sebesar 0,561 lebih dari $\alpha=$ 0,05 . Tingkat signifikasi lebih dari 0,05 , maka hipotesis ke-9 ditolak. Penelitian ini membuktikan bahwa change of directors tidak berpengaruh terhadap terjadinya fraudulent financial reporting.

Hal ini dikarenakan perusahaan sampel mungkin melakukan pergantian direksi bukan disebabkan karena perusahaan ingin menutupi kecurangan yang dilakukan direksi sebelumnya, tetapi perusahaan ingin adanya perbaikan kinerja dengan cara mengganti direksi lama dengan direksi baru yang dianggap lebih berkompeten dan dapat bekerja secara maksimal.

Hasil penelitian ini mendukung penelitian yang dilakukan oleh Tessa dan Harto (2016), serta
Yesiariani dan Rahayu (2016), namun tidak mendukung hasil penelitian yang dilakukan oleh Ulfah et,al (2017).

\section{Frequent Number of CEO's Pictures Tidak Berpengaruh Terhadap Flaudulent Financial Reporting \\ Variabel frequent number of CEO's picture} (CEOPIC) menunjukkan koefisiensi regresi sebesar 0,13 dengan tingkat signifikasi sebesar 0,364 lebih dari $\alpha=0,05$. Tingkat signifikasi lebih dari 0,05 , maka hipotesis ke-10 ditolak. Penelitian ini membuktikan bahwa frequent number of CEO's picture tidak berpengaruh terhadap terjadinya fraudulent financial reporting.

Semakin banyak CEO perusahaan, maka semakin banyak ide-ide yang ada untuk menjalankan perusahaan, apabila ide tersebut saling menguntungkan satu sama lain secara garis besar menguntungkan perusahaan, maka tidak akan timbul kecurangan dalam penyusunan laporan keuangan perusahaan.

Hasil penelitian ini mendukung penelitian yang dilakukan oleh Ulfah et,al (2017), namun tidak mendukung hasil penelitian yang dilakukan oleh Tessa dan Harto (2016), serta Siddiq, et al (2017).

\section{SIMPULAN}

Berdasarkan hasil yang diuji menggunakan analisis regresi logistik, maka hasil penelitian ini menunjukkan terdapat satu variabel yang berpengaruh terhadap fraudulent financial reporting yaitu Financial targets. Variabel Financial stability, External pressure, Personal financial needs, Nature of industry, Ineffective monitoring, Quality of external auditor, Change in auditor, Change of directors, Frequent number of CEO's pictures tidak berpengaruh terhadap fraudulent financial reporting.

Penelitian ini tidak terlepas dari berbagai keterbatasan. Berikut ini merupakan penjelasan mengenai beberapa keterbatasan yang dihadapi.

1. Penelitian ini hanya dilakukan selama tiga tahun pengamatan yaitu selama tahun 2014 sampai 2016. Penelitian selanjutnya diharapkan untuk menambah rentang waktu penelitian agar dapat memperoleh hasil yang lebih signifikan. 
2. Penelitian ini hanya menggunakan satu jenis industri yaitu sektor manufaktur yang terdaftar di Bursa Efek Indonesia, sehingga kurang mampu menggambarkan kondisi perusahaan secara keseluruhan.

3. Penelitian ini menggunakan proksi restatement untuk mengukur fraudulent financial reporting.

4. Model dalam penelitian ini baru 6,8\% yang menerangkan pengaruh Sembilan faktor risiko kecurangan terhadap fraudulent financial reporting dan sisanya masih terdapat $93,2 \%$ faktor lain yang mempengaruhi. Penelitian selanjutnya diharapkan menggunakan alat uji keuangan lainnya agar memperoleh hasil lebih maksimal.

Berdasarkan beberapa keterbatasan penelitian yang telah dijelaskan, maka penulis memberikan saran untuk penelitian selanjutnya:

1. Penelitian selanjutnya diharapkan menambah rentang waktu pengamatan agar memperoleh hasil yang lebih signifikan.

2. Penelitian selanjutnya diharapkan menggunakan sampel data dari sector lain seperti sector pemerintahan dimana sering terjadi adanya praktik fraud.

3. Penelitian selanjutnya diharapkan menggunakan proksi lain dalam mengukur fraudulent financial reporting agar mendapatkan hasil yang lebih baik dan membentuk model pendeteksian fraudulent financial reporting dengan lebih akurat.

4. Penelitian selanjutnya disarankan untuk menggunakan alat uji keuangan lain yang mungkin dapat berpengaruh terhadap fraudulent financial reporting pada sektor manufaktur.

\section{REFERENSI}

Annisya, et al. 2016. "Pendeteksian Kecurang Laporan Keuangan Menggunakan Fraud Diamond". Jurnal Ekonomi dan Bisnis (JBE), Hal. 72 - 89 Vol.23, No.1. ISSN: 1412-3126.

Apriyuliana, Atika. 2017. Mendeteksi Fraudulent Financial Reporting Dengan Analisis Faktor Risiko Kecurangan Teori Fraud Pentagon. Skripsi. Padang : Politeknik Negeri Padang.
Badrus, Ahmad. 2017. Model Pendeteksian Fraudulent Financial Statement Menggunakan Analisis Fraud Pentagon. Skripsi. Jakarta : Universitas Islam Negeri Syarif Hidayatullah.

Devy, et al. 2017. "Pengaruh Frequent Number Of Ceo's Picture, Pergantian Direksi Perusahaan Dan External Pressure Dalam Mendeteksi Fraudulent Financial Reporting (Studi Empiris Pada Perusahaan Farmasi Yang Listing Di Bei Periode 2012-2016)". e-Journal S1 Ak Universitas Pendidikan Ganesha. Vol: 8 No: 2.

Hartoyo, Fransisca. 2016. Analisis Pentagon Fraud Dalam Mendeteksi Fraudulent Financial Reporting Pada Perusahaan Manufaktur Yang Terdaftar Di Bursa Efek Indonesia Periode 2011-2015. Skripsi. Surabaya : Universitas Katolik Widya Mandala.

Herviana, Ema.2017. Fraudulent Financial Reporting : Pengujian Teori Fraud Pentagon Pada Badan Usaha Milik Negara (Bumn) Yang Terdaftar Di Bursa Efek Indonesia (Bei) Periode 2012-2016. Skripsi. Jakarta : Universitas Islam Negeri Syarif Hidayatullah.

Husmawati, Pera. 2017. Analisis Fraud Pentagon Dalam Mendeteksi Kecurangan Laporan Keuangan. Skripsi. Padang : Politeknik Negeri Padang.

Kusumaningrum dan Murtanto. 2016. “Analisis Pengaruh Fraud Diamond Dalam Mendeteksi Kecurangan Laporan Keuangan". Seminar Nasional dan Call Paper Fakultas Ekonomi UNIBA Surakarta. ISBN : 978- 979- 1230- 36- 0

Putriasih,et al. 2016. “Analisis Fraud Diamond Dalam Mendeteksi Financial Statement Fraud : Studi Empiris Pada Perusahaan Manufaktur Yang Terdaftar Di Bursa Efek Indonesia (Bei) Tahun 2013-2015". e-JournalS1 Ak Universitas Pendidikan Ganesha Jurusan Akuntansi Program S1 Vol:6 No:3.

Sanusi, Anwar. 2011. Metodologi Penelitian Bisnis. Jakarta: Salemba Empat. 
Saputra dan Kesumaningrum. 2017. "AnalisisfaktorFaktor Yang Mempengaruhi Fraudulent Financial Reporting Dengan Perspektif Fraud Pentagon Pada Perusahaan perbankan yang Terdaftar Di Bursa Efek Indonesia Tahun 20112015". Jurnal Akuntansi dan Keuangan, Vol. 22. No. 2.

Siddiq, et al. 2017. "Fraud Pentagon Dalam Mendeteksi Financial Statement". Seminar Nasional dan The 4th Call for Syariah Paper. ISSN 2460-0784.

Sihombing, Kennedy Samuel. 2014. "Analisis Fraud Diamond Dalam Mendeteksi Financial Statement Fraud : Studi Empiris Pada Perusahaan Manufaktur Yang Terdaftar Di Bursa Efek Indonesia (Bei) Tahun 2010-2012". Diponegoro Journal Of Accounting Volume 02, Nomor 02. ISSN (Online): 2337-3806.

Tessa dan Harto. 2016. "Fraudulent Financial Reporting: Pengujian Teori Fraud Pentagon Pada Sektor Keuangan Dan Perbankan Di Indonesia”. Simposium Nasional Akuntansi XIX, Universitas Lampung, Lampung, 26-27 Agustus.

Ulfah, et al.2017. "Pengaruh Fraud Pentagon Dalam Mendeteksi Fraudulent Financial Reporting (Studi Empiris Pada Perbankan Di Indonesia Yang Terdaftar Di Bei”. Forum Ilmiah Pendidikan Akuntansi Vol 5 No 1 Oktober 2017 Hlmn. 399-418. e-ISSN: 2337-9723

Widiyanti, Gustia. 2016. Analisis Elemen Fraud Diamond Dalam Mendeteksi Financial Statement Fraud (Studi Empiris Perusahaan Manufaktur Pada Bursa Efek Indonesia Tahun 2012-2014). Skripsi tanpa bab pembahasan. Lampung : Universitas Lampung.

Yesiariani dan Rahayu. 2016. "Analisis Fraud Diamond Dalam Mendeteksi Financial Statement Fraud (Studi Empiris pada Perusahaan LQ-45 yang Terdaftar di Bursa Efek Indonesia Tahun 2010 - 2014)". Simposium Nasional Akuntansi XIX, Universitas Lampung, Lampung, 26-27 Agustus. 